\title{
Hubungan Dukungan Keluarga Dan Aktifitas Sosial Terhadap Kemandirian Dalam Pemenuhan Activity Daily Living Pada Lansia Yang Menderita Diabetes Militus Tipe li Di Puskesmas Rawat Inap Mariat
}

\author{
Ryan Y.Z Logaritma ${ }^{1}$, O. Lopulalan ${ }^{2}$ \\ 1,2 Jurusan Keperawatan Politeknik Kesehatan Sorong \\ Email: ryanepid@gmail.com
}

\begin{abstract}
:
Diabetes Mellitus (DM) is a degenerative disease that continues to increase prevalence throughout the world and most are classified as type 2 DM. Increased DM cases as a change in lifestyle and diet. In this study discussed the relationship between family support and social activities with the incidence of type 2 diabetes mellitus. This study used quantitative with cross sectional design. This study was conducted on the elderly at Mariat Inpatient Health Center. Research Objectives: to find out family relationships and social activities with independence in fulfilling daily living activities (ADL) in the elderly who receive Diabetes Militus. This study uses a cross sectional method. The sampling technique used was total sampling with a sample of 31 people. Analyzed using the chi squard test with $\alpha=0.05$. The results of the statistical test using chi squard obtained a value of $\mathrm{p}=0,000$ for family support and a value of $\mathrm{p}=0.014$ for social activities. There is a relationship between family support and social activities towards independence in the fulfillment of daily life activities in the elderly who suffer from Diabetes Militus.
\end{abstract}

Keywords: Elderly, family support, social activities, independence, Diabetes Militus

Abstrak:

Diabetes Mellitus (DM) adalah penyakit degeneratif yang terus meningkat prevalensinya di seluruh dunia dan sebagian besar tergolong DM tipe 2. Peningkatan kasus DM tersebut sebagai akibat perubahan gaya hidup dan pola makan masyarakat. Pada penelitian ini diteliti hubungan antara dukungan keluarga dan aktifitas sosial dengan kejadian DM tipe 2. Penelitian ini menggunakan pendekatan kuantitatif dengan desain cross sectional. Penelitian ini dilakukan pada para lansia di Puskesmas Rawat Inap Mariat. Tujuan Penelitian : untuk mengetahui hubungan dukungan keluarga dan aktifitas sosial dengan kemandirian dalam pemenuhan activity daily living (ADL) pada lansia yang menderita Diabetes Militus. Penelitian ini menggunakan metode cross sectional. Teknik pengambilan sampel yang digunakan adalah total sampling dengan sample sebesar 31 orang. Di analisis menggunakan uji chi squard dengan $\alpha=0,05$. Hasil uji statistic menggunakan chi squard diperoleh $\mathrm{p}$ value $=0.000$ untuk dukungan keluarga dan $\mathrm{p}$ value $=0.014$ untuk aktifitas social. Ada hubungan antara dukungan keluarga dan aktifitas sosial terhadap kemandirian dalam pemenuhan activity daily living pada lansia yang menderita Diabetes Militus.

Kata Kunci : Lansia, dukungan keluarga, aktifitas sosial, kemandirian, Diabetes Militus

\section{PENDAHULUAN}

Diabetes melitus adalah salah satu dari masalah kesehatan utama pada masyarakat modern di dunia. Angka penderita diabetes melitus di dunia tercatat 382 juta jiwa menderita penyakit ini pada 2013 dan diperkirakan jumlahnya akan meningkat secara signifikan menjadi 592 juta jiwa pada tahun 2035 (Guariguata, et al., 2013).

enurut American Diabetes Association (ADA) (2005), Diabetes Melitus (DM) merupakan suatu kelompok penyakit metabolik dengan karakteristik hiperglikemia yang terjadi karena kelainan sekresi insulin, kerja insulin atau kedua-duanya. Hiperglikemia kronik pada diabetes berhubungan dengan kerusakan jangka panjang, disfungsi atau kegagalan beberapa organ tubuh, terutama mata, ginjal, saraf, jantung, dan pembuluh darah (Soegondo, 2013: 19).

Global status report on NCD World Health Organization (WHO) tahun 2010 melaporkan bahwa diabetes melitus menduduki peringkat ke6 sebagai penyebab kematian di dunia dengan sekitar 1,3 juta orang meninggal akibat diabetes melitus dan 4 persen meninggal sebelum usia 70 tahun. Pada Tahun 2030 diperkirakan diabetes melitus menempati urutan ke-7 penyebab kematian dunia (Kemenkes, 2013).

Pada tingkat dunia dan Indonesia, peningkatan kejadian Diabetes Militus juga tercermin ditingkat provinsi khususnya Provinsi Papua Barat. Berdasarkan surveilans rutin penyakit tidak menular berbasis rumah sakit di Papua Barat tahun 2010, Diabetes Militus termasuk dalam urutan keempat penyakit tidak menular terbanyak yaitu sebesar 7,15\% dan urutan kelima 
terbesar penyakit tidak menular penyebab kematian yaitu sebesar 6,85\%. Bahkan pada tahun 20112, Diabetes Militus menjadi penyebab kematian tertinggi penyakit tidak menular di Papua Barat yaitu sebesar 41,56\% .Hasil study pendahuluan yang dilakukan di Puskesmas Rawat Inap Distrik Mariat didapatkan jumlah lansia yang menderita diabetes militus pada 2 tahun terakhir yaitu 2016 dan 2017 berjumlah 29 orang, dan pada 3 bulan terakhir ini yaitu dari bulan Januari sampai Maret 2018 bertambah 2 orang, maka jumlah lansia yang menderita diabetes militus di Puskesmas Rawat Inap Mariat berjumlah 31 orang.

\section{METODE}

Jenis penelitian yang dugunakan adalah analitik dengan pendekatan cross sectional yaitu desain penelitian yang pengukuran variabelvariabelnya dilakukan hanya satu kali, pada satu saat tertentu (Sastroasmoro, 2010), sampel penelitian menggunakan total populasi sebanyak 31 responden. Data dianalisis dengan menggunakan SPSS, diuji dengan cqi square Fisher exat test dengan batas $\alpha=0,05$.

\section{HASIL}

Tabel 1.1 Hubungan dukungan keluarga dengan kemandirian dalam pemenuhan Activity Daily Living pada lansia yang menderita Diabetes Militus di Puskesmas Rawat Inap Mariat

\begin{tabular}{ccccccc}
\hline \multirow{2}{*}{$\begin{array}{c}\text { Dukunga } \\
\text { Keluarga }\end{array}$} & \multicolumn{4}{c}{ Kergantun } & \multicolumn{3}{c}{ Mandiri } & \multicolumn{2}{c}{ Jumlah } \\
& $\mathbf{F}$ & $\mathbf{\%}$ & $\mathbf{F}$ & $\boldsymbol{\%}$ & $\mathbf{N}$ & $\mathbf{\%}$ \\
\hline Tidak & 6 & $100 .($ & 0 & 0 & 6 & 100.0 \\
Ya & 1 & 4.0 & 24 & 96.0 & 25 & 100.0 \\
Total & 7 & 22.6 & 24 & 77.4 & 31 & 100.0 \\
\hline $\boldsymbol{\alpha}=\mathbf{0 . 0 5}$ & \multicolumn{6}{c}{$\boldsymbol{p}=\mathbf{0 . 0 0 0}$}
\end{tabular}

Berdasarkan tabel 1.1 diatas dapat diketahui bahwa responden yang mendapatkan dukungan keluarga dan hidup mandiri berjumlah 24 orang (96.0\%), lebih banyak dari responden yang mendapat dukungan keluarga namun masih bergantng dengan orang lain dengan jumlah 1 orang $(4.0 \%)$, sedangakan responden yang tidak mendapatkan dukungan keluarga namun hidup mandiri berjumlah 6 orang $(100 \%)$, lebih banyak dari responden yang tidak mendapatkan dukungan keluarga namun tergantung pada orang lain dengan hasil tidak adanya responden.

Hasil uji statistic Fisher exat test diperoleh nilai $\mathrm{p}=0,000(\mathrm{p}<\alpha 0,05)$ ini berarti ada hubungan yang signifikan antara dukungan keluarga terhadap kemandirian dalam pemenuhan
Activity Daily Living pada lansia yang menderita Diabetes Militus di Puskesmas Rawat Inap Mariat kabupaten Sorong.

Tabel 1.2. Hubungan dukungan antivitas social terhadap kemandirian dalam pemenuhan Activity Daily Living pada lansia yang menderita Diabetes Militus di Puskesmas Rawat Inap Mariat

\begin{tabular}{|c|c|c|c|c|c|c|}
\hline \multirow{3}{*}{$\begin{array}{l}\text { Activitas } \\
\text { Sosial }\end{array}$} & \multicolumn{4}{|c|}{ Kemandirian } & \multirow{2}{*}{\multicolumn{2}{|c|}{ Jumlah }} \\
\hline & \multicolumn{2}{|c|}{$\begin{array}{c}\text { Tergantu } \\
\text { g }\end{array}$} & \multicolumn{2}{|c|}{ Mandiri } & & \\
\hline & $\mathbf{F}$ & $\%$ & $\mathbf{F}$ & $\%$ & $\mathbf{N}$ & $\%$ \\
\hline Tidak & 4 & 66.7 & 2 & 33.3 & 6 & 100.0 \\
\hline $\mathrm{Ya}$ & 3 & $12 . C$ & 22 & 88.0 & 25 & 100.0 \\
\hline Total & 7 & 22.6 & 24 & 77.4 & 31 & 100.0 \\
\hline$\alpha=0.05$ & & & & $=0$ & & \\
\hline
\end{tabular}

Berdasarkan tabel 4.2 diatas dapat diketahui bahwa responden yang melakukan activitas social dan hidup mandiri berjumlah 22 orang $(88.0 \%)$, lebih banyak dari responden yang melakukan activitas social namun bergatung dengan orang lain berjumlah 3 orang (12.0\%), sedangkan yang tidak melakukan activitas social dan hidup mandiri berjumlah 2 orang (33.3\%), lebih banyak dari yg tidak melakukan aktifitas social namun bergantung dengan orang lain berjumlah 4 orang $(66.7 \%)$

Hasil uji statistik Fisher exat test diperoleh nilai $p=0,014(p<\alpha 0,05)$ berarti ada hubungan yang signifikan antara aktifitas sosial terhadap kemandirian dalam pemenuhan Activity Daily Living pada lansia yang menderita Diabetes Militus di Puskesmas Rawat Inap Mariat.

\section{PEMBAHASAN}

Dukungan keluarga adalah sebuah proses yang terjadi sepanjang masa kehidupan,sifat dan jenis dukungan berbeda dalam berbagai tahaptahap siklus kehidupan. Dukungan keluarga dapat berupa dukungan sosial internal, seperti dukungan dari suami, istri atau dukungan dari saudara kandung dan dapat juga berupa dukungan keluarga eksternal bagi keluarga inti. Dukungan keluarga membuat keluarga mampu berfungsi dengan berbagai kepandaian dan akal.sebagai akibatnya, hal ini meningkatkan kesehatan dan adaptasi keluarga (Friedman, 2010).

Berdasarkan tabel 4.5, dari jumlah total 31 responden didapatkan reponden memiliki 
dukungan keluarga yang baik adalah 24 orang atau $96.0 \%$, pada penelitian ini menunjukkan ada hubungan yang signifikan antara dukungan keluarga terhadap kemandirian lansia yang menderita Diabetes Militus dapat dilihat dari hasil statistic yaitu $\mathrm{P}=0,000$. Adapun hasil pada penelitian ini sejalan dengan penelitian yang dilakukan oleh (Damayanti, Nursiswati, \& Kurniawan (2015)) yang juga menunjukkan hasil bahwa dukungan keluarga terhadap pasien diabetes melitus dengan kategori baik karena dalam penelitiannya menunjukkan bahwa jumlah total 40 responden yang memiliki dukungan keluarga terhadap pasien Diabetes militus sebanyak 38 responden atau 96\%. Kemudian, penelitian yang dilakukan (Shofiyah \& Kusuma (2014)) juga menunjukkan bahwa dukungan keluarga terhadap kepatuhan pasien dalam penatalaksanaan DM berada pada kategori baik dan mendukung dalam penelitianya peneliti menggunakan jumlah responden 30 dan sebanyak 22 responden yang memiliki dukungan keluarga terhadap penyakit Diabetes Militus atau sebanyak $73,3 \%$.

Tingginya angka Dukungan keluarga terhadap pasien DM yaitu pada karekteristik masyarakat Indonesia yang cenderung memiliki ikatan kekeluargaan yang erat dan akrab membuat sumber dukungan keluarga akan mudah diperoleh oleh penderita DM tipe 2 khususnya (Damayanti, Nursiswati, \& Kurniawan, 2015). Selain itu, sifat mendasar keluarga berupa motivasi untuk memberikan dukungan terhadap keluarga yang memiliki masalah terhadap kesehatannya sangat tinggi sehingga menunjukkan bahwa dukungan keluarga terpenuhi (Shofiyah \& Kusuma, 2014). Selain itu, keluarga adalah penyedian layanan kesehatan primer bagi anggota keluarga. Sehingga pada penelitian ini keluarga telah dapat sepenuhnya melaksanakan fungsi perawatan keluarga dengan memberikan dukungan yang baik (Kaakinen et al, 2010)

Depkes RI (2003) dalam Maryam dkk (2009) memberikan kategori lansia menjadi 3 kelompok umur yang terdiri dari : pralansia (prasenilis) yaitu lansi usia antara 45-59 tahun, lansia yaitu dengan usia 60 tahun atau lebih, dan lansia resiko tinggi ialah seseorang yang berusia 70 tahun atau lebih/seseorang yang berusia 60 tahun atau lebih dengan masalah kesehatan. Lansia bukan suatu penyakit, namun merupakan tahap lanjut dari suatu proses kehidupan yang ditandai dengan penurunan kemampuan tubuh untuk beradaptasi dengan stressor di lingkungan. Dengan semakin bertambahnya usia, maka Lansia akan mengalami proses menuan, dimana proses penuaan merupakan suatu proses biologis yang tidak dapat dihindari. Pengaruh proses menuan pada Lansia dapat menimbulkan berbagai masalah, kemampuan fisiknya akan semakin menurun sehingga dapat mengakibatkan kemunduran pada peran-peran sosialnya.

Aktivitas sosial Didefinisikan sebaagai kegiatan yang dilakukan bersama dengan masyarakat di lingkungan sekitar. Aktivitas sosial merupakan salah satu dari aktivitas sehari - hari yang dilakukan oleh lansia. Contoh aktivitas sehari-hari yang berkaitan dengan aktivitas sosial yang dikemukan oleh Marthuranath (2004) dalam Activities of Daily Living Scale for Elderly People adalah lansia mampu berinteraksi dengan lingkungan sekitarnya

bersama lansia lainnya atau orang-orang terdekat, menjalankan hobi serta aktif dalam aktivitas kelompok. Menurut Yuli (2014) teori aktivitas atau teori kegiatan (activity theory) menyatakan bahwa lansia yang selalu aktif dan mengikuti banyak kegiatan sosial adalah lansia yang sukses.

Aktivitas sosial didefinisikan sebagai kegiatan yang dilakukan bersama dengan masyarakat di lingkungan sekitar. Aktivitas sosial merupakan salah satu dari aktivitas sehari - hari yang dilakukan oleh lansia. Contoh aktivitas seharihari yang berkaitan dengan aktivitas sosial yang dikemukan oleh Marthuranath (2004) dalam Activities of Daily Living Scale for Elderly People adalah lansia mampu berinteraksi dengan lingkungan sekitarnya

bersama lansia lainnya atau orang-orang terdekat, menjalankan hobi serta aktif dalam aktivitas kelompok. Menurut Yuli (2014) teori aktivitas atau teori kegiatan (activity theory) menyatakan bahwa lansia yang selalu aktif dan mengikuti banyak kegiatan sosial adalah lansia yang sukses.

Berdasarkan tabel 4.6, dari jumlah total 31 responden didapatkan reponden yang melakukan

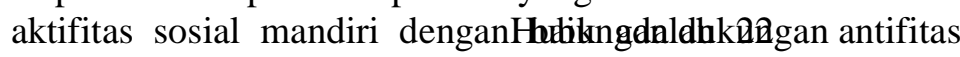
orang atau $88.0 \%$, penelitian ini menunjukkan adanya hubungan aktifitas sosial terhadap kemandirian lansia penderita Diabetes Militus dengan nilai signifikan $\alpha=0.05>\mathrm{p}=0.014$. Penelitian ini sejalan dengan penelitian yang dilakukan oleh (Afifah Alfyanita dkk 2016) bahwa ada hubungan yang signifikan antara tingkat kemandirian dalam melakukan aktifitas sosial pada lansia.

\section{SIMPULAN}

1. Ada hubungan yang signifikan antara hubungan Dukungan Keluarga terhadap 
kemandirian dalam pemenuhan Activity Daily Living pada lansia yang menderita Diabetes Militus di Puskesmas Rawat Inap Mariat

2. Ada hubungan yang signifikan antara hubungan Aktifitas Sosial terhadap kemandirian dalam pemenuhan Activity Daily Living pada lansia yang menderita Diabetes Militus di Puskesmas Rawat Inap Mariat

\section{SARAN}

Saran yang dapat diberikan terkait dengan hasil penelitian ini adalah sebagai berikut :

1. Bagi Responsen Puskesmas Rawat Inap Mariat. Diharapkan buat responden untuk lebih aktif dalam melakukan kegiatan sosial serta sering memeriksakan kesehatan dan mengikuti kegiatan yang diadakan oleh pihak Puskesmas.

2. Bagi Puskesmas Rawat Inap Mariat. Diharapkan Puskesmas mampu memberikan lebih jadwal pemeriksaan kesehatan khususnya untuk pemeriksaan Diabetes Militus untuk para lansia, memberikan jadwal untuk kesehatan jasmani seperti senam lansia agar responden lebih sehat.

3. Bagi peneliti selanjutnya. Diharapkan lebih meningkatkan penelitian yang serupa dengan menambah variabel-variabel yang belum diteliti sehingga akan didapatkan hasil penelitian lebih sempurna.

\section{DAFTAR PUSTAKA}

Gustaviani,Lewis,dkk,P. (2012). Manifestasi Klinis DM. Pembahasan Manifestasi Klinis Diabetes Mellitus, (2011), 16-62.

Soegondo dkk, 2004. Diagnosa dan Klasifikasi Diabetes Mellitus Terkini Dalam Penatalaksanaan Diabetes Mellitus Terpadu Sebagai Panduan Penatalaksanaan Diabetes Mellitus Bagi Dokter Maupun Eduktor, Jakarta, hal 17-28.
Kementerian Kesehatan, 2013. Petunjuk Teknik Pengukuran Faktor Resiko Diabetes Mellitus.

Friedman,M.2010. Buku Ajar Keperawatan Keluarga Riset, Teori dan Praktek Edisi ke-5. Jakarta: EGC.

Knakinet et al. (2012). GAYA Hidup Pada Penderita Diabetes Mellitus, 1-205.

Maryam dkk.2010. Buku Ajar Keperawatan Keluarga Riset, Teori dan Praktek: EGC.

Kurnia, Damayanti. Dkk., Epidemiologi dan Faktor-faktor Resiko Terjadinya Diabetes Mellitus Tipe 2 dalam Naskah Lengkap Diabetes Mellitus ditinjau dari berbagai Aspek Penyakit Dalam. Semarang: Balai Penerbit Undip; 2007.

Kusuma dkk, 2007., Panduan Gerintologi. Jakarta: Pustaka Utama, 